\title{
CUSTOMIZATION: IMPACT ON PRODUCT AND PROCESS PERFORMANCE
}

\author{
Vishwanath G. Hegde \\ College of Business and Economics, California State University, Hayward, CA 94542, \\ vhegde@csuhayward.edu, Phone: 510-885-4912, Fax: 510-885-4796
}
Sunder Kekre
Tepper School of Business, Carnegie Mellon University, Pittsburgh, PA 15213, skekre@cmu.edu , Phone: 412-268-3586, Fax: 412-268-7345

\author{
Surendra Rajiv \\ NUS Business School, National University of Singapore, Singapore 117592, srajiv@nus.edu.sg, \\ Phone: (65) 6874-3169, Fax: (65) 6779-5941 \\ Pandu R. Tadikamalla \\ Katz Graduate School of Business, University of Pittsburgh, Pittsburgh, PA 15260, \\ pandu@katz.pitt.edu, Phone: 412-648-1596, Fax: 412-624-36
}

November 2005 


\begin{abstract}
Manufacturing capability has often been viewed to be a major obstacle in achieving higher levels of customization. Companies follow various strategies ranging from equipment selection to order management to cope with the challenges of customization. We examine how the customization process affects product performance and conformance in the context of a design-to-order manufacturer of industrial components. Our competing risk hazard function model incorporates two thresholds, which we refer to as mismatch and manufacturing thresholds. Product performance was adversely affected when the degree of customization exceeded the mismatch threshold. Likewise, product conformance eroded when the degree of customization exceeded the manufacturing threshold. Relative sizes of the two thresholds have implications for the investments by firms to improve their customization capabilities. Our research presents a rigorous framework to address two key questions relevant to the implementation of product customization: (1) what degrees of customization to offer, (2) how to customize the design process.

(CUSTOMIZATION; DESIGN-TO-ORDER; PRODUCT PERFORMANCE; PRODUCT

CONFORMANCE; COMPETING RISK HAZARD FUNCTION MODEL)
\end{abstract}




\section{Introduction}

Customization strategy is increasingly being pursued by industries to gain competitive advantage. A fairly high degree of product customization is facilitated in almost all industry segments today. Popularity of customization stems from a marketing desire to achieve a better fit between customer needs and the product offering. Customer satisfaction is expected to increase with the improved fit between the product offering and customer requirements, provided the manufacturer can facilitate customization within a reasonable cost (Pine, 1993).

It is evident from the recent literature that a variety of strategies have been proposed to cope with the adverse impacts of customization on manufacturing. For example, Swaminathan (2001) presents a framework to facilitate customization using standardized operations utilizing process and product modularity. Point of customer involvement in product design, manufacturing and the delivery process is another critical variable that impacts the product and process modularization. Duray et al. (2000) proposes customization strategies based on the point of customer involvement. Gilmore and Pine (1997) propose customization strategies, which are based on the degree of changes to product design and product representation. Swaminathan and Tayur (1988), and Lee and Billington (1994) present late product differentiation techniques to mitigate the negative impact of customization on supply chain performances. Pine (1993) highlights the need to investment in flexible manufacturing systems, information technologies and modular product design in order to facilitate customization. 
Clearly, a large body of research has been reported on acquiring manufacturing capability to facilitate customization. However, there is a paucity of work on the efficacy of customization from a front-end process perspective. The willingness to pay a premium price for customized products largely depends on the higher performance quality of the product (Chakravarty and Kumar, 2002). The achievement of higher product performance through tailoring the product to unique customer needs is essential for generating the demand for and bringing about the success of customization. Customization involves the identification of individual customer's needs and then subsequently satisfying the needs through appropriate product modifications. An example of this is seen in Fisher (1994), wherein the customization process at National Bicycle is described in detail. Bicycles at National Bicycle are designed by acquiring customer specific parameters through automated measuring technologies in the retail outlets. In such cases, the customer provides the key technical parameters of the product such as individual physical dimensions, body posture and specification of the gear trains. This allows the manufacturer to suitably modify standardized frame designs and manufacturing processes to provide the performance and conformance sought by customers.

However, as Zipkin (2001) states, elicitation of customer requirements is hard and often customers have trouble articulating their requirements. Contrary to the popular viewpoint, higher degrees of customization may not always result in higher performance and customer satisfaction due to complexity of the customization process. The complexity of the customization process can potentially limit the degree to which customization is beneficial to customers (Zipkin, 2001). We investigate this aspect in our field study. Specifically, our research investigates two key 
unexplored research questions identified by Ramdas (2003): (1) what degrees of customization to offer and (2) how to customize the design process. We investigate these questions from a quality perspective.

The objective of our research is to examine the efficacy of product customization in light of the complexity of the customization process. We investigate how customization affects the two key dimensions of quality: performance and conformance (Garvin, 1987). Specifically the following two questions are analyzed. First, does the complexity of the customization process limit the degree of customization that is beneficial from product performance point of view? Here we find that up to a limit, which we define as the mismatch threshold, customization does improve the product performance. Beyond this threshold, customization is found to be detrimental and escalates mismatch errors (decreases product performance). Second, does the manufacturing capability limit the degree of customization from a product conformance point of view? ${ }^{1}$ Here we find that up to a limit, which we define as the manufacturing threshold, customization does not create adverse impacts. Beyond this threshold, customization strains the capabilities of the manufacturing systems thereby decreasing product conformance. Further, we also examine the relative sizes of the two thresholds (mismatch and manufacturing) and derive implications on investments to improve customization capabilities.

Our field study examined these issues at a large manufacturer of industrial iron and steel rolls. The research site was a designed-to-order (DTO) industrial component-manufacturing

\footnotetext{
${ }^{1}$ Flexible manufacturing systems will increase the manufacturing threshold. However, the relationship between the manufacturing threshold and flexible manufacturing systems is not examined in this paper.
} 
environment. The physical and metallurgical specifications of the rolls were unique to each order. Product customization was implemented by allowing the customer to choose a set of metallurgical parameters. The number of metallurgical parameters specified by the customer was a proxy for the degree of customization of rolls. The product modification necessary for customization resulted in a tension between the customer's performance requirements and the inhouse capability of the manufacturing processes to deliver conformance. A short fall in meeting customer requirements led to mismatch errors. Likewise a short fall in the incapability to conform by the manufacturing process led to manufacturing errors. Either of these short falls led to roll breakages in the field. These breakages are classified into either mismatch errors or manufacturing errors.

We investigated the drivers of both these two types of failures - mismatch errors, those where the customization does not meet the performance desired by the customer, and manufacturing errors, those where the manufacturing process does not achieve conformance. The impact of these drivers was analyzed using a competing risk hazard function model. The model parameters were estimated using the primary data. The estimated model quantified the relative magnitude of both types of failures. In particular the following key insights emerged:

- A mismatch threshold exists. Customization up to this threshold, improves performance quality and decreases mismatch errors. However, beyond this threshold, further customization increases mismatch errors. Customization beyond this threshold is thus counterproductive from a performance viewpoint. 
- Another threshold defined as the manufacturing threshold also exists. Customization up to this threshold does not decrease manufacturing quality. Beyond this threshold however, an increase in customization escalates manufacturing errors.

- At our site, the mismatch threshold was found to be smaller than the manufacturing threshold. Thus the mismatch threshold was far more restrictive. This implies that the manufacturer should investigate opportunities to invest in front-end process technologies such as product configurators in Design-to-Order (DTO) environments.

The above findings have important managerial implications on the implementation of customization. The recent drive to enhance manufacturing capabilities and cope with the adverse impact of customization seems to have extended the manufacturing threshold. In such cases, the manufacturing process is not restrictive. However, the front-end product customization process and its associated complexity limit the degree of customization that is beneficial to customers. The degree of customization in such cases is limited by customization eliciting mechanisms. This study finds empirical evidence to support Zipkin's (2001) viewpoint that elicitation and the customization process itself may impose limitations on customization. Our research thus presents a rigorous framework to answer two key unexplored research questions identified by Ramdas (2003) from a quality perspective. The development of a mismatch threshold, a manufacturing threshold and identifying the drivers of these thresholds can help companies decide the degree of customization to offer and improve the customization process. 
The rest of the paper is organized as follows. In §2, we develop a conceptual framework and formulate hypotheses in the context of our research site. In $\S 3$, we describe the econometric analysis. In §4, we report the results and discuss the managerial implications. In the final section, we conclude by summarizing the results, discussing the limitations of the study and identifying opportunities for future research.

\section{The Research Context and a Conceptual Framework}

\subsection{The Research Site}

The research site was a manufacturing company of iron and steel rolls. These rolls were designed to order based on the profile of a customer's rolling mill. Besides size and other physical characteristics, the rolls were designed to have metallurgical properties for a variety of grades of alloy steels and rolling campaigns of the customer. Customers were given choices to specify certain parameter values in the metallurgical specification such as alloy composition, hardness, molding and heat treatment variables. Some customers assumed this responsibility more than others and tailored their needs by selecting values matching their specific application requirements and mill conditions. The manufacturer, recognizing his process capability and customers' requirements, subsequently chose all the remaining parameters not set by the customer.

Customization of metallurgical parameters was thus important to both parties (customer and the roll manufacturer). The metallurgical parameters determine roll performance for the customer and the manufacturing performance for the manufacturer simultaneously. Shortcomings surfaced 
as field complaints when the rolls break or wear out prematurely. We classify such failures as either manufacturing errors or mismatch errors. Manufacturing errors arise when the manufacturer's production process is not capable of conforming to specifications set by the customer. Mismatch errors are the failures caused by non-manufacturing factors such design errors. The failure detected in the field triggers a battery of metallurgical tests that determine the causes of failures that fall into two categories: manufacturing or mismatch errors. Ambiguity in the classification occurred in less than 5 percent of the cases leading to either arbitration or protracted negotiations.

\subsection{Dimensions of the Designed-To-Order Process}

There are two drivers in the customization process: degree of customization and product complexity. We define these drivers in the context of the roll manufacturer.

\section{Degree of Customization}

As explained earlier, the customer participated in the customization process by specifying a subset of the metallurgical parameters. The total number of parameters varied depending upon the roll family and ranged from 9 to 22. The customers were given a choice to specify a subset of these parameters (30 to 60 percent) depending upon their specific needs and condition of the mill. The roll manufacturer incorporated values specified by the customer and determined the remaining parameters considering his internal process capability and the customer's requirements. 
In such a setting, we operationalize the degree of customization as follows:

$$
\text { CUSTOM }=\frac{\text { Number of metallurgical parameters set by the customer }}{\text { Total number of metallurgical parameters for the roll family }}
$$

Even within a roll family, some customers chose to participate more than others and specified a larger set of parameters values. The data revealed a wide range of customizations for the same product family. Figure 1 depicts the various degrees of customizations for a typical roll family.

Insert Figure 1 here

\section{Product Complexity $(P R O D X)$}

Rolls were ranked on a 1 to 5 scale to represent product complexity. The metallurgical group at the manufacturer established this ranking. The product complexity ranged from 1.2 to 4.8 and exhibited an average of 3.28. The product complexity ranking was jointly driven by the total number of parameters in the specification and the interdependencies among these parameters from metallurgical and mechanical standpoints. This product complexity measurement is consistent with the design engineering literature. Product complexity has three main elements: (1) the size of the design problem, that is the number of design parameters, (2) correlation among the design parameters, that is the interdependencies, and (3) variability in the design parameters (El-Haik and Yang , 1999; Suh, 1990). The product complexity here captures the level of difficulty associated with the design-engineering problem. 
In summary, the CUSTOM variable measures the degree of design flexibility utilized by the customer for the given roll family. However, rolls from different roll families with the same CUSTOM value could vary in terms of design complexity. The PRODX variable accounts for the differences in design complexities arising from the number of parameters and their interdependencies. $^{2}$

\section{$2.3 \quad$ Roll Failures and Customization}

We discuss, next, the impact of customization on roll failures detected in the field. As explained earlier, metallurgical tests firmly attribute the failures to either manufacturing or mismatch. The manufacturing errors result from poor conformance quality (manufacturing defects) where as the mismatch errors result from poor product performance caused by non-manufacturing reasons. The impact of customization on both these failure types is hypothesized next.

\section{Customization and Mismatch errors}

We conjecture that with increased customization, mismatch errors first decrease up to the mismatch threshold. Beyond this threshold however, mismatch errors start escalating rapidly. The rationale for this trajectory is as follows. The initial gains from allowing the customer to select parameters can be attributed to the customer's deeper knowledge of his/her rolling operations. The customers also have a better understanding of the sensitivity of specific roll parameters to their individual rolling mill conditions. This knowledge lies more with the customer than the roll manufacturer, thus eliciting these values from the customer results in

\footnotetext{
${ }^{2}$ We thank the referees for pointing out this aspect.
} 
lower misapplications. Von Hippel (1998) has highlighted this aspect in CTI (Computer Telephony Integration) and ASIC (application-specific integrated circuit) production environments. Typical failures that are reduced in region 1 (Figure 2) are listed in Table 1.

Insert Figure 2 and Table 1 here

For a particular product with given number of parameters, a higher degree of customization means the customer has to select a larger set of parameter values. As the number of parameters established by the customer increases in region 2 (Figure 2), the inter-dependencies among parameters become less manageable. This aspect has been emphasized in House-of-Quality literature (Hauser and Clausing, 1988). This leads to higher chances of design errors during the customization process. We therefore conjecture that the customer is able to leverage gains from customization up to the mismatch threshold. Beyond this threshold, the complexity associated with the interdependencies dominates and the failure rate rises negating the earlier gains. The typical failures in region 2 (Figure 2) are listed in Table 1. The relationship between the degree of customization (CUSTOM) and the mismatch errors is summarized in the following hypothesis.

HYPOTHESIS 1: The probability of a mismatch error first decreases with an increase in the degree of customization up to a threshold level called the mismatch threshold. Beyond this threshold, the mismatch errors increase with higher degrees of customization. 


\section{Customization and Manufacturing Errors}

The manufacturing capability at a roll manufacturer typifies a flexible manufacturing system that can handle a variety of roll families. As MacDuffe et al. (1996) points out, such systems provide a range of flexibility where variety does not cause any detrimental effects up to a certain level. We also, integrate concepts from Swaminathan (2001) who underscores the importance of product and process modularity. In our context, modularity in customization is the ability to accommodate a range of choices in the metallurgical parameters set by customers within the constraints of the manufacturer's standard routings. The manufacturer can achieve metallurgical modularity by allowing the customers to select their own specific values for a set of metallurgical parameters. The manufacturer adjusts the remaining parameters to deploy their own standard routings to ensure conformance quality. However, customization beyond a threshold strains the capability of manufacturing processes. Standardized routings developed for product families cannot accommodate the highly customized metallurgical specifications without sacrificing conformance quality. Thus, manufacturing errors escalate if degree of customization exceeds the threshold level as shown in region 4 (Figure 2). Typical failure modes in this region 4 are listed in Table 1. This leads to the following hypothesis:

HYPOTHESIS 2: The probability of a manufacturing error increases with the degree of customization only beyond a certain threshold level called the manufacturing threshold.

Product complexity is defined as a property of an object with many interwoven element, aspects, details, or attributes that make the whole object difficult to understand (Suh 1990). With higher levels of product complexity, the interdependencies among the product parameters are far more 
difficult to manage. Additionally, the management of product-application mapping and productmanufacturing process mapping becomes far more difficult to manage with products of higher complexity (El-Haik \& Yang, 1999). The deterioration of performance and conformance with increased degree of customization occurs much sooner with higher product complexity. It suggests that the thresholds mismatch as well as manufacturing as portrayed in Figure 2, are more restrictive with higher level of product complexity. This is reflected in the next hypothesis:

HYPOTHESIS 3: Both the customization threshold and manufacturing threshold decrease with higher level of product complexity.

\section{Data Collection and Econometric Model}

\subsection{Variable Definitions and the Conceptual Model}

For our study, we chose a random sample of over 3000 rolls sold to 150 customers over a span of 2 years. We collected primary data at the roll level on the following variables. The transaction data such as shipment date and customer's rolling mill attributes were obtained from the MRP system. Other records for the MRP transactions were obtained from various data sources in the company. Description of the variables and their data sources are described below:

- Degree of Customization (CUSTOM): This is the ratio of number of metallurgical parameters set by customer to the total number of metallurgical parameters required to specify roll in the product family. 
- Failure Time (FTIME): It is the time between the shipping date and complaint date as measured in days. The MRP system provided shipment dates where as the customer complaint documents provided the complaint date.

- Cause of Failure (CAUSE): This variable indicates the cause of failures. The resolved failure modes were classified into mismatch and manufacturing errors. This is a categorical variable ( 0 - not yet failed, 1-mismatch failure \& 2-manufacturing failure). The failure mode data was obtained from the internal documentation maintained by the engineering department.

- Product Complexity (PRODX): This variable indicates the metallurgical complexity of the rolls on a scale of 1 to 5 .

Failure times for mismatch errors and manufacturing errors are the dependent variables in the model. The objective of our empirical model is to understand the relationship between the degree of customization (CUSTOM) and product complexity (PRODX) on the probability of a mismatch error and manufacturing error. The relationship between the dependent and the independent variables are expressed as follows:

$$
\begin{aligned}
& \text { Probability of a Mismatch Error }=f(C U S T O M, P R O D X) \\
& \text { Probability of a Manufacturing Error }=f(C U S T O M, P R O D X)
\end{aligned}
$$

\subsection{Empirical Model Specification: Competing Risks Approach}

The objective of our empirical analysis is to quantify the impact of design-to-order (DTO) process on the probability of roll failure in either mode. Specifically, we model separately the impact of the degree of customization (CUSTOM) and product complexity (PRODX) on the 
probability of both mismatch error and manufacturing error. As noted earlier, for each roll, the data contained information on whether the roll failed during the observation period, and in the case of roll failure, the cause and time of failure (mismatch or manufacturing).

The following data characteristics influenced our econometric model specification: (1) the dependent variable is a measure of the duration from one state to another, i.e., the duration between product shipment to product failure, (2) the presence of multiple causes of roll failure; in particular roll failure due to a mismatch error or manufacturing error, and (3) the presence of observations on rolls which did not fail during the observation period. In these cases, there is an upper truncation on the failure time. We employed the competing risk hazard function formulation (Kalbfleisch and Prentice, 1983; Cox and Oakes, 1984), which is routinely used in reliability and quality engineering to analyze product failure data (Juran \& Gryna, 1993). The competing risk hazard function model involves a specification for failure time distributions. We have chosen the Weibull hazard functions, which are defined as:

$$
\mathrm{h}_{\mathrm{j}}(\mathrm{t})=\lambda_{j} \gamma_{j}\left(\lambda_{j} t\right)^{\gamma_{j}-1}
$$

Where, $\mathrm{j}=1$ for Mismatch $\& \mathrm{j}=2$ for Manufacturing. The competing risks hazard function model is estimated through maximum likelihood method (Kalbfleisch and Prentice, 1983; Cox and Oakes, 1984). 


\subsubsection{Incorporating the Impact of Explanatory Variables and Interpretation of Parameters}

As shown above, the Weibull density function is characterized by the two parameters $\gamma_{j}$ and $\lambda_{j}$. We use the proportional hazard specification to incorporate the impact of explanatory variables on the hazard. The $\lambda_{j}$ for mismatch errors and manufacturing errors are specified as

$$
\begin{aligned}
& \lambda_{1}=\exp \left(\alpha_{0}+\alpha_{1} \times C U S T O M+\alpha_{2} \times \text { PRODX }\right) \\
& \lambda_{2}=\exp \left(\beta_{0}+\beta_{1} \times C U S T O M+\beta_{2} \times P R O D X\right)
\end{aligned}
$$

\subsubsection{Incorporating Mismatch and Manufacturing Thresholds}

As hypothesized earlier, the likelihood of a roll failure due to mismatch errors decreases with an increase in CUSTOM up to a threshold point, which we defined as the mismatch threshold $(\theta)$. However, for values of CUSTOM above $\theta$, an increase in CUSTOM increases the failure probability. We incorporate this aspect by modifying equation (4):

$$
\begin{aligned}
\lambda_{1} & =\exp \left(\alpha_{0}+\alpha_{1 L} \times(\theta-\text { CUSTOM })+\alpha_{2} \times \text { PRODX }\right) \text { for CUSTOM } \leq \theta \\
& =\exp \left(\alpha_{0}+\alpha_{1 U} \times(C U S T O M-\theta)+\alpha_{2} \times \text { PRODX }\right) \text { for CUSTOM }>\theta
\end{aligned}
$$

The mismatch threshold is not directly observable in the data. Therefore, the mismatch threshold ( $\theta$ ) needs to be estimated endogenously. To capture these unobserved differences, we employ a random effect specification. This is accomplished by assuming $\theta$ to be Beta distributed with parameters $\mu$ and $\rho$ where

$$
\mu=\exp \left(\omega_{0}+\omega_{1} \times P R O D X\right)
$$


Notice that the parameter $\mu$ is a function of product complexity as shown in (7). Therefore the mismatch threshold $(\theta)$ is driven by product complexity. The expected mismatch threshold $(\bar{\theta})$ is the expectation of the Beta distribution, which is given by:

$$
\bar{\theta}=\frac{\rho}{\rho+\mu}
$$

Similarly, for the manufacturing errors we hypothesized, that up to a threshold level, any increase in CUSTOM does not increase manufacturing errors. We have defined this threshold to be the manufacturing threshold $(\eta)$. For values of CUSTOM above this threshold, however, increase in CUSTOM increases the failure probability. We incorporate this aspect by modifying equation (5):

$$
\begin{aligned}
\lambda_{2} & =\exp \left[\beta_{0}+\beta_{1} \times(C U S T O M-\eta)+\beta_{2} \times P R O D X\right] \text { with } \beta_{1}>0 \text { for CUSTOM }>\eta \\
& =\exp \left[\beta_{0}+\beta_{2} \times P R O D X\right] \text { for CUSTOM } \leq \eta
\end{aligned}
$$

Similar to the mismatch threshold, we define the manufacturing threshold $(\eta)$ to be Beta distributed with parameters $\xi$ and $\kappa$ where

$$
\xi=\exp \left(\varsigma_{0}+\varsigma_{1} \times P R O D X\right)
$$

The expected manufacturing threshold $(\bar{\eta})$ is the expectation of the Beta distribution, which is given by:

$$
\bar{\eta}=\frac{\kappa}{\kappa+\xi}
$$

The probability density functions can be calculated once the parameters of the hazard functions are estimated. The hazard function model specification and the expected impact of the explanatory variables on the probability of failures are summarized in table 2. 
Insert Table 2 here

\section{Results and Managerial Implications}

\subsection{Specification Tests and Discussion of the Findings}

The maximum likelihood estimates, the log likelihood values of proposed models and specification tests results are presented in Table 3. Incorporation of the mismatch threshold and manufacturing threshold improves the explanatory power of the model significantly. The likelihood ratio test strongly supports the presence of the thresholds and rejects the baseline models. The significance of the mismatch threshold $(\theta)$ can be observed through the significance of the parameters that influence the parameter $\mu$ of the beta distribution. Also, the parameters $\alpha_{1 L}$ and $\alpha_{1 U}$ are very significant. These results together provide a strong support for hypothesis 1 . The significance of the manufacturing threshold ( $\eta$ ) can be observed through the significance of the parameters that influence the parameter $\xi$ of the beta distribution. Among the parameters of manufacturing errors, the parameter for CUSTOM $\left(\beta_{1}\right)$ is positive and significant, indicating an adverse impact of customer's technical specification on manufacturing errors beyond the manufacturing threshold $(\eta)$. These results strongly support Hypothesis 2.

Insert Table 3 here 


\subsection{Sensitivity of Mismatch and Manufacturing Errors to the Degree of Customization}

The estimates of parameter values in the competing risk hazard function model are presented in Table 3. Figures $3 \& 4$ show the sensitivity of roll failure to varying degree of customization computed from the estimated parameter values. The curves reconfirm the hypothesized impacts of degree of customization and product complexity on the roll performances.

Insert Figure 3 and 4 here

Consider the case of mismatch errors shown in Figure 3, which shows the probability of roll failure occurring within a year due to mismatch error by the customer. Two curves (for PRODX = 4 Vs. 2) are computed to show the adverse impact of product complexity. In both cases, initially, we observe that product performance gains are achieved by allowing the customer to select certain parameters. Thus mismatch errors decrease with higher levels of customization in both cases. These decreasing trends continue up to the mismatch threshold, beyond which the adverse impact of customization dominates and the mismatch errors start increasing. The graphs also highlight the added burden of product complexity. Two detrimental impacts are observed. First, rise in the error rate occurs much earlier as seen from the lower mismatch threshold (for PRODX $=4$ Vs. 2). Second, the rise in the error rate after the threshold is steeper confirming that interaction of degree of customization and product complexity are far more severe after the threshold.

The managerial implication of the above phenomena is that customization should be encouraged up to a point. Seeking information from the customer, who has a better knowledge of the rolling 
mill conditions, can significantly reduce mismatch errors. However, permitting too many choices to the customer results in a higher-level of mismatch. The complexity in the specification of the parameter values becomes overwhelming to the customer due to interdependencies. This is consistent with Zipkin's (2001) description of the limitations of elicitation process and its adverse impact in situations of high degrees of customization. In complex products, the adverse impact is far more pronounced. This suggests that the manufacturer should offer a limited choice set of parameters to the customer in cases of complex products.

Likewise, manufacturing errors are dormant up to a threshold as shown in Figure 4. The manufacturing system and the standardized process routings of the manufacturer can accommodate the customization up to the manufacturing threshold. Any changes by the customer beyond this threshold rapidly escalate the failures due to manufacturing errors. Product complexity aggravates the failure rate as shown by the comparison of two curves (PRODX $=4$ Vs. 2). The threshold decreases and the failures escalate at a steeper rate for higher product complexity. The managerial conclusion from Figure 4 is that investments in flexible manufacturing and process engineering have allowed the roll manufacturer to permit customization up to a certain degree. However, there is a substantial price to be paid for over taxing the manufacturing systems to a higher degree of customization.

\subsection{Restricting Threshold - Is It Mismatch or Manufacturing?}

The existence of both thresholds raises an important issue concerning which of the two thresholds is more restrictive. The size of the two thresholds is a function of product complexity 
as characterized in equations (8) and (11). Figure 5 presents a plot of the size of the mismatch and manufacturing thresholds for varying levels of product complexity using our estimated model. Our field site represents a manufacturing environment with high product complexity ${ }^{3}$. We observe that in such cases mismatch threshold is lower than the manufacturing threshold for the complexity levels to the right of " $A$ " in Figure 5. However, this also suggests that if the roll complexities were to be low and to the left of A, the relative sizes of thresholds would flip. The manufacturing threshold would then become more restrictive.

Insert Figure 5 here

The managerial implication is that with low levels of product complexity, customization is hampered by the ability of the manufacturing systems to handle the choices made by the customer. From an investment standpoint, our study underscores the need to invest in flexible manufacturing system and process engineering for environments represented by the region to the left of the crossover point A. However, we recommend investment in eliciting technologies and front-end process technologies, to the right of the crossover point A. These front-end process technologies such as configurators, would assist the customer in handling a larger set of interdependent parameter set.

Insert Table 4 here

\footnotetext{
${ }^{3}$ Average product complexity was 3.28, which is to the right of crossover point A.
} 
We want to highlight the fact that product complexity partially explains the positioning of the two thresholds. A number of other factors can also drive the positioning of the two thresholds. Table 4 presents a list of potential drivers of the thresholds based on the literature (Ramdas, 2003; Von Hippel, 2001 \& Thomke and Von Hippel, 2002). We have not included these drivers into our model due to limitation of the data. Understanding the impact of these drivers on the thresholds would be valuable in designing the customization process.

\section{Conclusions}

The success of customization depends upon providing low costs of customization while achieving higher product quality simultaneously. In this research, we have analyzed the impact of customization on product quality at a manufacturing plant for an industrial component. The research site was a design-to-order production environment where each order was custom designed. We found that if errors were made during the elicitation of customer requirements, the product redesign to match the requirements, and manufacturing led to failures in the field. These failures, classified either as mismatch or manufacturing, were driven by two factors: degree of customization and product complexity.

A competing risks hazard function model was estimated using extensive data on field failures. Mismatch failures were found to decrease initially by allowing the customer to make choices, in which case customization was beneficial. The data also revealed a threshold, which we defined as mismatch threshold, beyond which customization was detrimental. Mismatch errors increase 
significantly if customization was carried to levels beyond the threshold. Product complexity reduced the threshold and also amplified the negative impact of higher levels of customization. Customization also impacted manufacturing errors beyond a threshold. Up to this threshold, the manufacturing systems were flexible to cope with the customization choices made by the customer. The existence of the two thresholds and their relative sizes has implications for investment choices in improving the customization capabilities of the roll manufacturer. Our research thus developed a rigorous framework to address the two key unexplored research questions identified by Ramdas (2003) from the quality perspective: (1) what degrees of customization to offer and (2) how to customize the design process.

We exercise caution in generalizing our results and point out some limitations of this research. First, we have validated the concepts based on the data from one manufacturing firm. Examination of the customization processes and their impact on quality in other environments is necessary to further confirm and replicate our results. Second, the research site represents an environment in which the components are expensive and the errors are rather objectively assessed. However, customer expectations may determine the mismatch curve in a product environment where product performance is more subjective. Finally, we have used probability of errors as the measure of product performance because of the unavailability of cost data. The forms and the relative positions of the curves might change substantially if costs of field failures were assessed. 
We have developed a rigorous framework to analyze the impact of customization on quality in an industrial component market based on primary data. The insights of this study have a major implication on the implementation of customization from both marketing and manufacturing viewpoints. Our research, we believe is one step towards better understanding of the drivers of enhanced customization performance.

\section{References}

Cox, D. R. AND D. OAKES (1984), Analysis of Survival Data, Chapman and Hall, London.

Chakravarty, A. K. AND K. R. Kumar (2002), "Customer Satisfaction Through Design, Manufacturing and Supply Networks: Introduction to the Special Issue”, Production and Operations Management, 11, 3, 289-292.

Duray, R., Ward, P. T., Milligan, G. W. and W. L. Berry (2000), “Approaches to Mass Customization: Configurations and Empirical Validation,” Journal of Operations Management, 18, 6, 605-625.

EL-HAIK, B AND K. YANG (1999), “The components of complexity in engineering design”, IIE Transactions, 31, 10, 925-934.

FISHER, M. L. (1994), National Bicycle Industrial Co., a case study, The Wharton School, University of Pennsylvania, Philadelphia.

Garvin, D. A (1987), "Competing on the Eight Dimensions of Quality," Harvard Business Review, 65, 6, 101-109. 
Gilmore, J. H. AND B. J. Pine II (1997), “The Four Faces of Mass Customization,” Harvard Business Review, 75, 1, 91-101.

Hauser, J. R. And D. Clausing (1988), “The House of Quality,” Harvard Business Review, 66, 3, 63-71.

Juran, J. M. AND F. M. GRYNA (1993), Quality Planning and Analysis: From Product Development through Use, $2^{\text {nd }}$ edition, McGraw-Hill, New York, NY.

Kalbfleisch, J. D. And R. L. Prentice (1983), The Statistical Analysis of Failure Time Data, John Wiley and Sons, New York, NY.

LeE, H. L. And C. BiLlington (1994), “Designing Products and Processes for Postponement,” in Management of Design: Engineering and Management Perspectives, S. Dasu and C. Charlesman editors, Kluwer Academic Publishers, Boston.

MacDuffie, J.P., Sethuraman, K. AND M. L. Fisher (1996), “Product Variety and Manufacturing Performance: Evidence from the International Automotive Assembly Plant Study,” Management Science, 42, 3, 350-369.

PInE, B. J. (1993), Mass Customization: The New Frontier in Business Competition, Harvard Business School Press, Boston.

RAmDAS, K (2003), “Managing Product Variety: An Integrative Review and Research Directions,” Production and Operations Management, 12, 1, 79-102.

SuH, N. P (1990), The Principles of Design, $1^{\text {st }}$ ed., Oxford University Press, New York.

Swaminathan, J. M. (2002), “Enabling Customization Using Standardized Operations,” California Management Review, 43, 3, 125-135. 
Swaminathan, J. M. And S. R. TAyur (1999), "Managing Design of Assembly Sequences for Product Lines that Delay Product Differentiation,” IIE Transactions, 31, 4, 1015-1026.

Swaminathan, J. M. AND S. R. TAYuR (1998), "Managing Broader Product Lines through Delayed Differentiation using Vanilla Boxes,” Management Science, 44, 12, S161-S172.

Thomke, S. AND E. Von Hippel (2002), “Customers as Innovators: A New Way to Create Value,” Harvard Business Review, 80, 4, 74-85.

VON Hippel, E. (1998), “Economics of Product Development by Users: The Impact of Sticky Local Information,” Management Science, 44, 5, 629-644.

VON HiPPEL, E. (2001), “PERSPECTIVE: User Toolkits for Innovation,” Journal of Product Innovation Management, 18, 4, 247-257.

ZIPKIN, P (2001), The Limits of Mass Customization,” MIT Sloan Management Review, 42, 3, 81-87. 
Figure 1: Customization at the Research Site

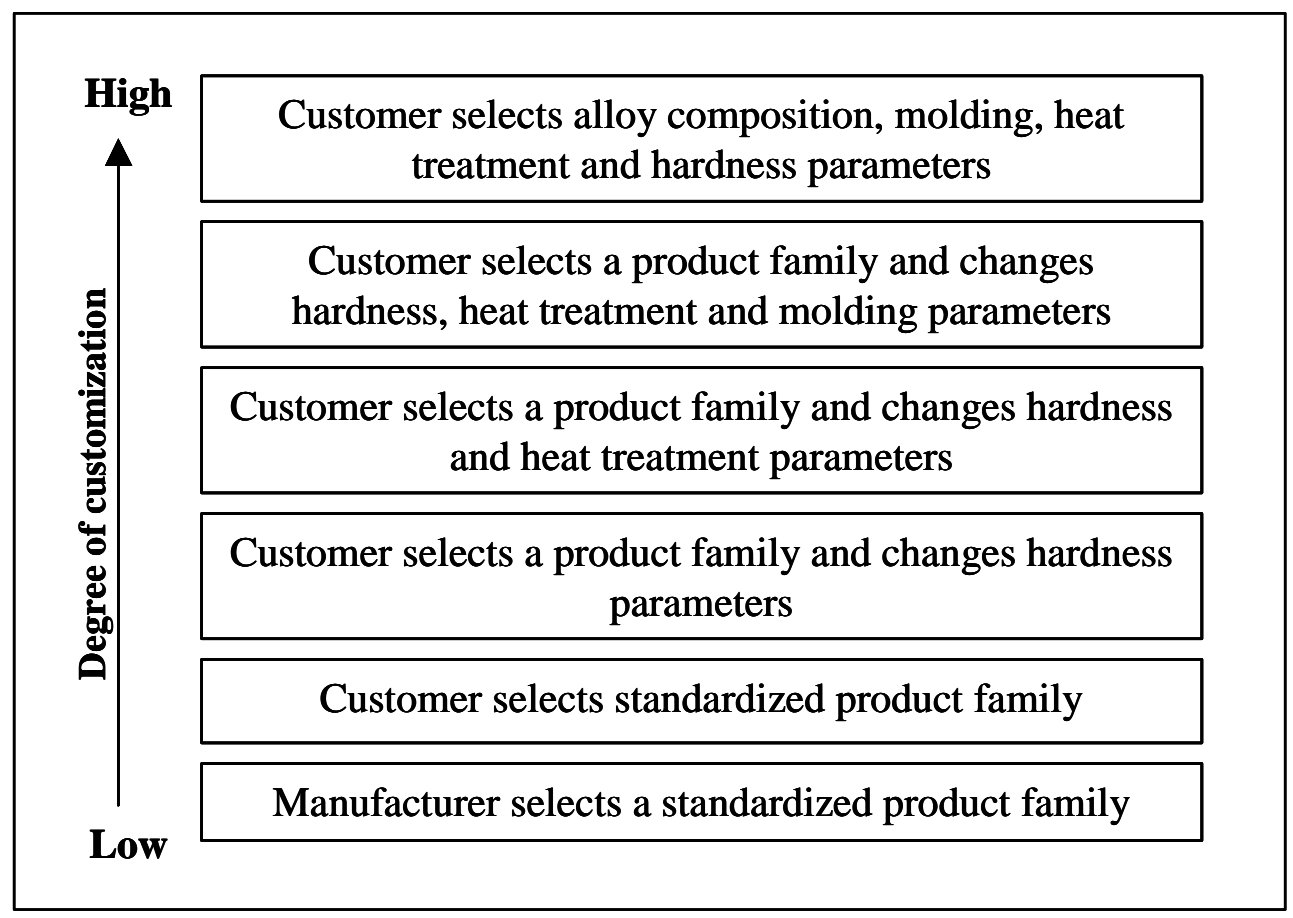

Figure 2: Impact of customization on field failures

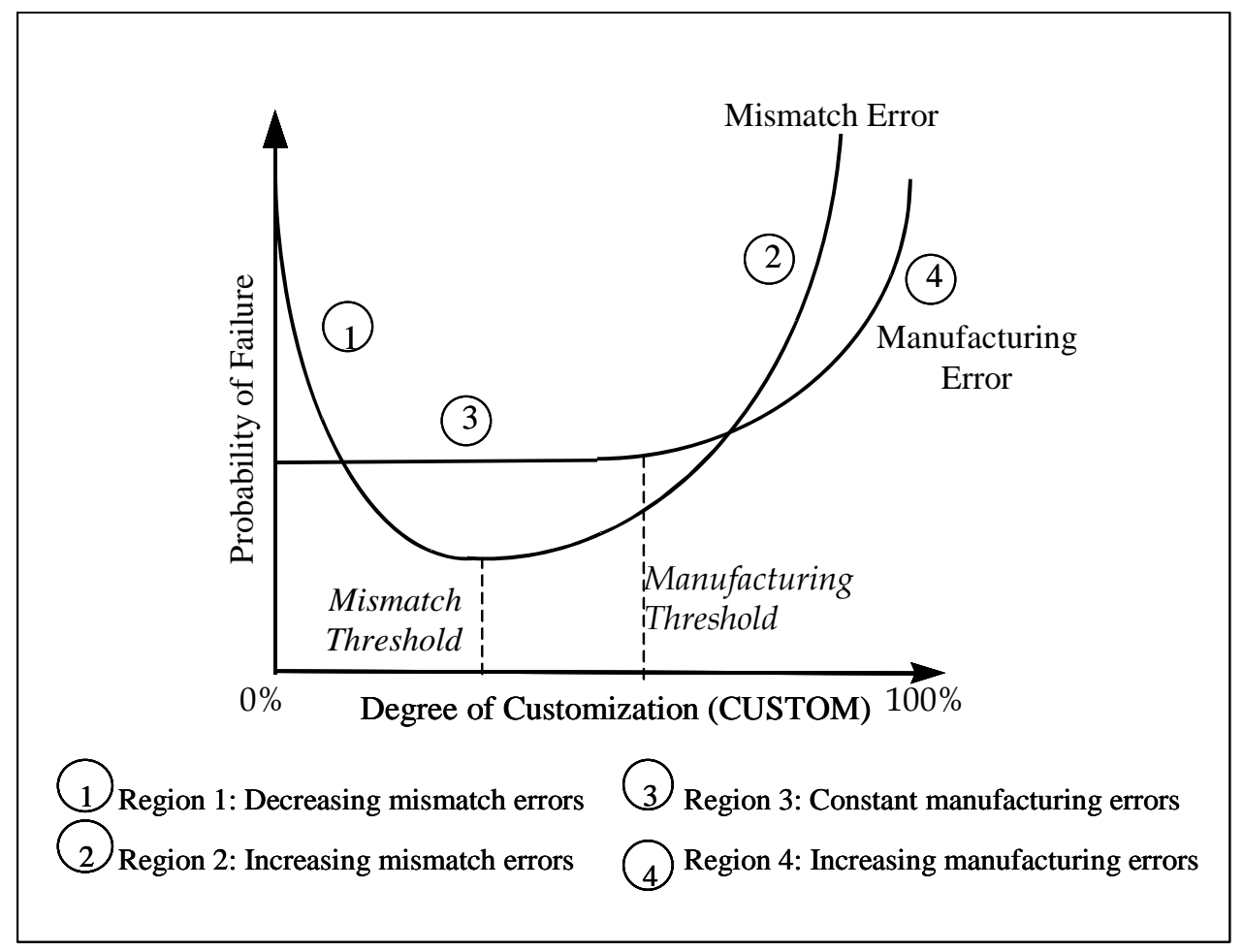


Figure 3: Sensitivity of Mismatch Errors to CUSTOM \& Product Complexity

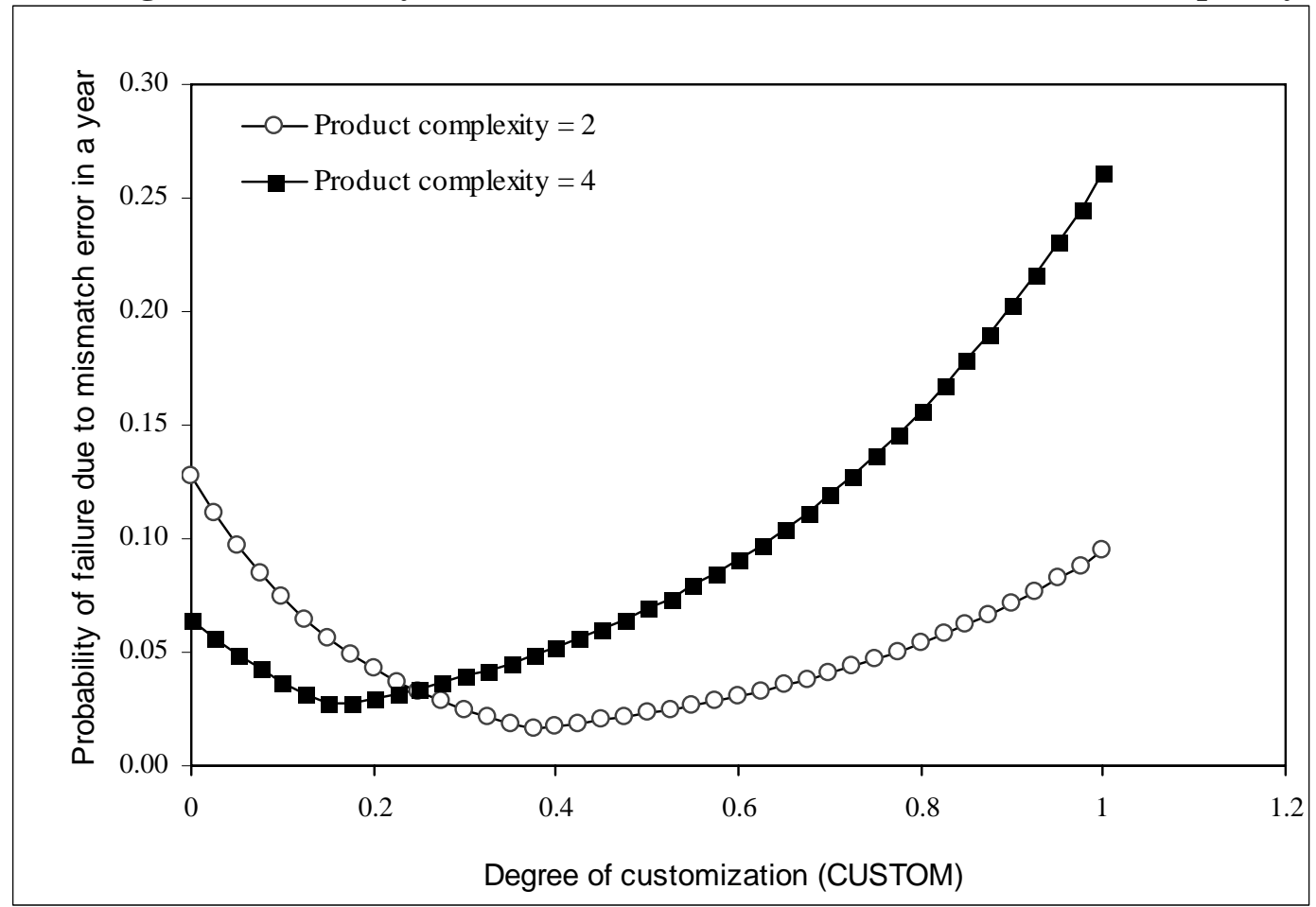

Figure 4: Sensitivity of Manufacturing Errors to CUSTOM \& Product Complexity

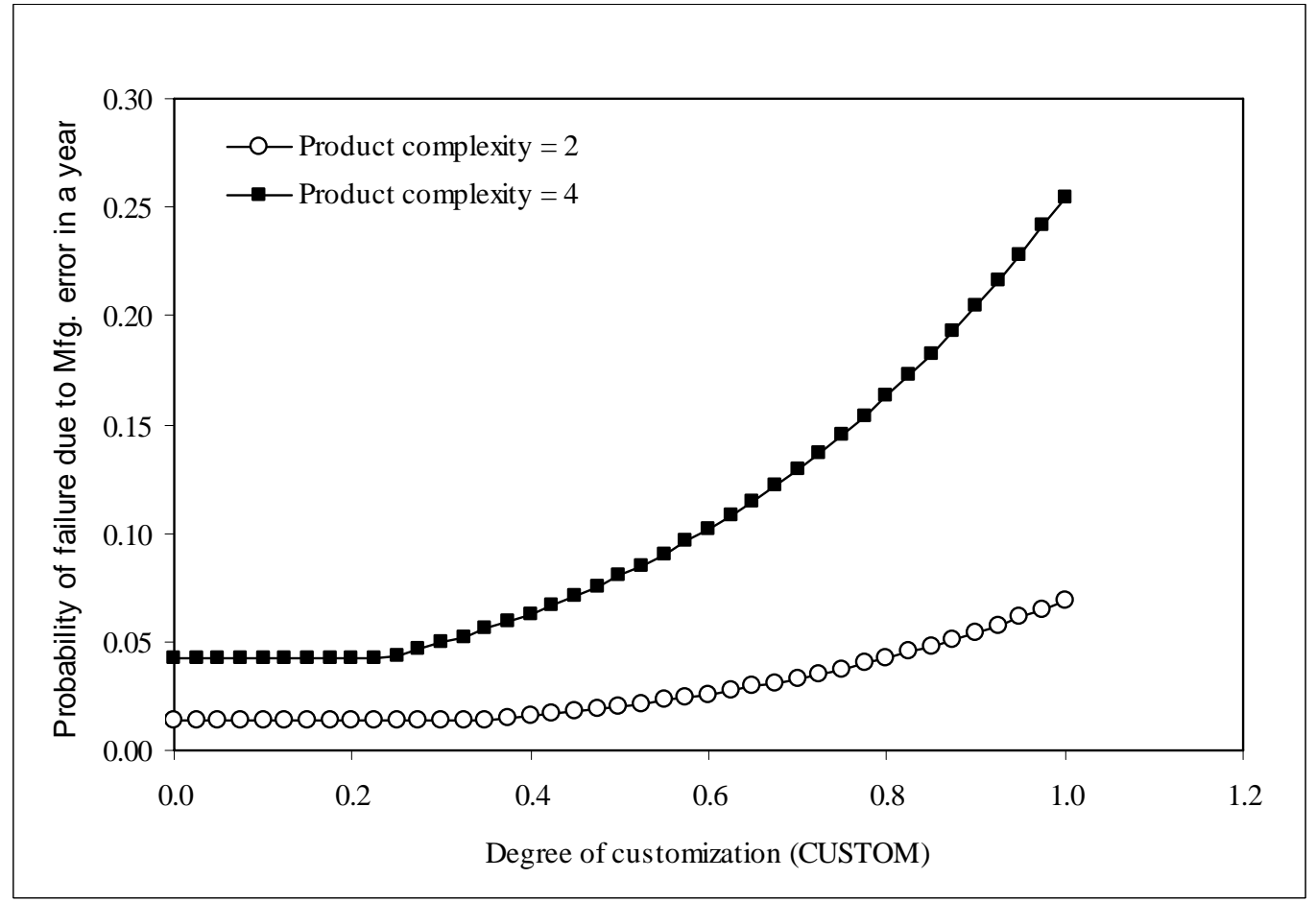


Figure 5: Sensitivity of Mismatch and Manufacturing Thresholds to Product Complexity

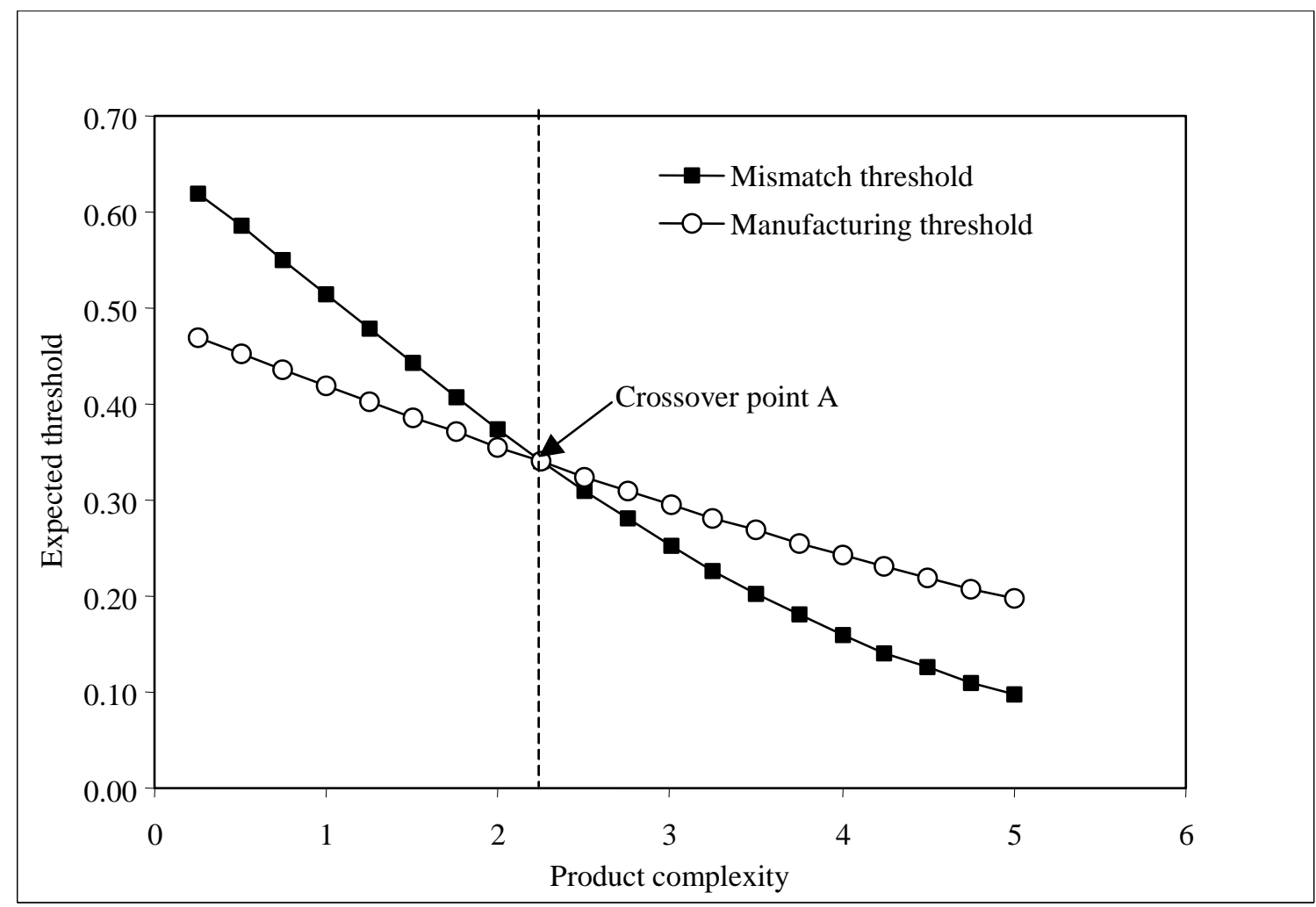


TABLE 1: Typical Types of Failures in Four Regions

\begin{tabular}{|c|l|}
\hline Region & \multicolumn{1}{|c|}{ Types of failures } \\
\hline $\mathbf{1}$ & $\begin{array}{l}\text { Pre-mature wear } \\
\text { Thermal cracks } \\
\text { Mini spall, edge spall, crumble spall and surface spall }\end{array}$ \\
\hline $\mathbf{2}$ & $\begin{array}{l}\text { Double-mould separation } \\
\text { Roll shaft breakage } \\
\text { Customer could not dress the roll } \\
\text { Thermal cracks } \\
\text { Shoulder Spalling }\end{array}$ \\
\hline $\mathbf{3}$ & $\begin{array}{l}\text { Blow holes } \\
\text { Excessive blow holes inside the roll body } \\
\text { Roll cracks originated from inside the roll body because of molding errors } \\
\text { Uneven wear } \\
\text { Hard spots } \\
\text { Neck cracks }\end{array}$ \\
\hline
\end{tabular}

TABLE 2: Hazard Function Model - Expected Impact of Explanatory Variables

\begin{tabular}{|c|c|c|c|c|}
\hline \multirow{2}{*}{ Error Type } & \multirow{2}{*}{$\begin{array}{c}\text { Factors } \\
\text { (Which influence } \\
\text { probability of failure) }\end{array}$} & \multicolumn{3}{|c|}{ Explanatory Variables } \\
\hline & & Variable name & $\begin{array}{c}\text { Expected sign of } \\
\text { the co-efficient }\end{array}$ & $\begin{array}{l}\text { Expected impact } \\
\text { on Factors }\end{array}$ \\
\hline \multirow{4}{*}{$\begin{array}{c}\text { Mismatch } \\
\text { errors }\end{array}$} & \multirow{3}{*}{ Failure rate $\left(\lambda_{1}\right)$} & CUSTOM $\leq \theta$ & + & Decrease \\
\hline & & CUSTOM $>\theta$ & + & Increase \\
\hline & & PRODX & + & Increase \\
\hline & $\begin{array}{l}\text { Mismatch threshold } \\
\qquad(\theta)\end{array}$ & PRODX & + & Decrease \\
\hline \multirow{3}{*}{$\begin{array}{l}\text { Manufacturing } \\
\text { errors }\end{array}$} & \multirow[t]{2}{*}{ Failure rate $\left(\lambda_{2}\right)$} & CUSTOM $>\eta$ & + & Increase \\
\hline & & PRODX & + & Increase \\
\hline & $\begin{array}{l}\text { Manufacturing } \\
\text { threshold }(\eta)\end{array}$ & PRODX & + & Decrease \\
\hline
\end{tabular}


TABLE 3: Estimates of the Competing Risk Hazard Function Model

\begin{tabular}{|c|c|c|c|c|}
\hline Error Type & Variable & Coefficient & $\begin{array}{l}\text { Baseline Model } \\
\text { (No thresholds) }\end{array}$ & $\begin{array}{c}\text { Baseline Model } \\
+ \\
\text { Thresholds } \\
\end{array}$ \\
\hline \multirow{8}{*}{$\begin{array}{l}\text { Mismatch } \\
\text { Errors }\end{array}$} & CONSTANT & $\alpha_{0}$ & $-15.7491^{*}$ & $-18.4491^{*}$ \\
\hline & CUSTOM & $\alpha_{1 L}$ & $-2.6581^{*}$ & 19.6581* \\
\hline & CUSTOM & $\alpha_{1 U}$ & - & $9.9844^{*}$ \\
\hline & PRODX & $\alpha_{2}$ & $1.7583^{*}$ & $0.8591^{*}$ \\
\hline & & $\gamma_{1}$ & $0.2907^{*}$ & $0.2891^{*}$ \\
\hline & CONSTANT & $\omega_{0}$ & - & $-0.0816 * *$ \\
\hline & PRODX & $\omega_{1}$ & - & $0.5721^{* *}$ \\
\hline & & $\rho$ & - & $1.7280^{*}$ \\
\hline \multirow{7}{*}{$\begin{array}{c}\text { Manufacturing } \\
\text { Errors }\end{array}$} & CONSTANT & $\beta_{0}$ & $-19.3610^{*}$ & $-20.3610^{*}$ \\
\hline & CUSTOM & $\beta_{1}$ & $4.4405^{*}$ & $8.3400^{*}$ \\
\hline & PRODX & $\beta_{2}$ & $1.7940 * *$ & $1.8750 *$ \\
\hline & & $\gamma_{2}$ & $0.3143^{*}$ & 0.3014* \\
\hline & CONSTANT & $\varsigma_{0}$ & - & $0.4630 *$ \\
\hline & PRODX & $\varsigma_{1}$ & - & $0.2701^{*}$ \\
\hline & & $\kappa$ & - & $1.5020 *$ \\
\hline \multicolumn{3}{|c|}{ Maximized Log Likelihood } & -1393.4851 & -1179.1051 \\
\hline \multicolumn{3}{|c|}{ Test statistic Value (comparison with Model I) } & & 214.38 \\
\hline \multicolumn{3}{|c|}{$\chi^{2}$ value at $1 \%$ significance level } & & 18.4753 \\
\hline
\end{tabular}

* Indicates significance level at 0.01 level, ** indicates significance level at 0.05 level

Table 4: Drivers of Mismatch Thresholds

\begin{tabular}{|l|l|}
\hline \multicolumn{1}{|c|}{ Category } & \multicolumn{1}{c|}{ Drivers } \\
\hline Product technology and architecture & $\begin{array}{l}\text { Modularity } \\
\text { Product life cycle phase (product maturity) }\end{array}$ \\
\hline Order generation (design) process & $\begin{array}{l}\text { Involvement of customer's technical personnel } \\
\text { Involvement of manufacturer's technical personnel }\end{array}$ \\
\hline Information and front-end technologies & $\begin{array}{l}\text { Product configurators } \\
\text { Design toolkits }\end{array}$ \\
\hline Complexity & $\begin{array}{l}\text { Manufacturing complexity } \\
\text { Application complexity }\end{array}$ \\
\hline
\end{tabular}

